\title{
Barus sebagai Titik Nol Islam Nusantara: Tinjauan Sejarah dan Perkembangan Dakwah
}

\author{
Uky Firmansyah Rahman Hakim \\ Program Pascasarjana Prodi Komunikasi Penyiaran Islam \\ UIN Sunan Kalijaga Yogyakarta
}

Korespodensi dengan Penulis:

Uky Firmansyah Rahman Hakim: Telp: 085363489011

E-mail: ukyfirmansyahrh@gmail.com

Keywords:
Da'wah,Nusanta
ra Islamic
History,
Indonesia, Barus.

Kata kunci:

Dakwah, Sejarah Islam Nusantara, Indonesia, Barus

\section{Abstract}

The decision to establish Barus City in Center of Tapanuli as the zero point of Islam Nusantra caused a mixed reaction from the Indonesian Historian. During this time the public knows that Islam first entered Indonesian territory in Aceh. But long before that the teachings of Islam already existed in Barus. This paper will provide an overview of the traces of the entry of Islamic teachings and evidence of the establishment of the Islamic Archipelago and the development of da'wah in Barus. Islam before being preached to Barus about the fifth century $B C$ in Barus as evidence is the site of Mahligai, Papan Tinggi, Makham Tuan Makhdum whose gravestone reads kaligarafi verses of the Koran. Sheikh Mahmud played a major role in providing Islamic teachings through trade in the city of Barus. At present the lack of preachers makes the glory of Islam in the City of Barus decline, recitation is also rarely done and adolescent association is also mixed. This study further explains the impact of the development of Barus in the present.

\footnotetext{
Abstrak

Keputusan penetapan Barus di Tapanuli Tengah sebagai titik nol Islam Nusantara menimbulkan reaksi beragam dari sejarawan Indonesia. Selama ini yang masyarakat mengetahui Islam pertama kali masuk wilayah Indonesia adalah di Aceh. Tulisan ini memberikan penjelasan mengenai jejak masuknya ajaran Islam dan bukti penetapan Islam Nusantara serta perkembangan dakwah di Barus. Islam sebelum didakwahkan ke Barus kira-kira abad kelima masehi di Barus sebagai buktinya adalah situs Mahligai, Papan Tinggi, Makham Tuan Makhdum yang nisannya bertuliskan kaligarafi Alquran. Syekh Mahmud berperan besar dalam memberikan ajaran Islam melalui perdagangan di Kota
} 
Barus. Saat ini kurangnya pendakwah membuat kejayaan Islam di Kota Barus mengalami kemunduran, pengajian juga jarang dilakukan dan pergaulan remaja juga juga campur-baur. Studi ini lebih lanjut menjelaskan dampak perkembangan Barus di masa sekarang.

\section{PENDAHULUAN}

Sejak zaman prasejarah, penduduk kepuluan Indonesia dikenal sebagai pelayar-pelayar yang sanggup mengarungi lautan lepas. Sejak awal abad masehi sudah ada rute-rute pelayaran dan perdagangan antara kepulauan Indonesia dengan berbagai daerah Asia tenggara.1Perdagangan tersebut juga sebagai jalan dakwah ke Indonesia. Dakwah merupakan aktivitas yang sangat penting dalam Islam. Dengan dakwah, Islam dapat tersebar dan diterima oleh manusia. Sebaliknya, tanpa dakwah Islam akan semakin jauh dari masyarakat dan selanjutnya akan lenyap dari permukaan bumi. Dalam kehidupan masyarakat dakwah berfungsi menata kehidupan yang agamis menuju terwujudnya masyarakat yang harmonis dan bahagia. ${ }^{2}$ Identitas Kultural suatu wilayah dan negara merupakan hal penting bagi ekstensi dan pengembangan dari wilayah tersebut. ${ }^{3}$ Sejarah dakwah membawa Islam ke Indonesia melalui pelayaran di lautan. Sejarah Islam di Indonsia perlu dipahami dan dimaknai oleh setiap masyarakat nusantara agar dapat belajar dari perjuanagan dakwah pada masa lampau. ${ }^{4}$

Pembangunan di masa lalu memberikan suatu penjelasan kepada kita bahwa pembagunan bukan mengahasilkan masyarakat desa yang sejahtera, adil dan makmur materil, dan spiritual, melainkan baru menghasilkan beberapa anggota sejatera adil dan makmur. ${ }^{5}$ Dakwah perjalanan dakwah sejak zaman Rasulullah SAW sampai sekarang telah melalui suatu proses yang sangat panjang dengan segala peristiwa yang melatarinya. Dakwah mempunyai dimensi yang penting untuk merealisasikan kondisi umat kearah yang diridhoi oleh Allah SWT yaitu, dimensi teosentris sekaligus antroposentris atau dalam bahasa agama

\footnotetext{
${ }^{1}$ Marwati Djoened Poesponegoro dan Nugroho Notosusanto (ed), "Sejarah Nasional Indonesia II", (Jakarta: Balai Pustaka, 1984), hlm 2.

2Moh. Ali Aziz, "Ilmu Dakwah", (Jakarta: Kencana, 2004), hlm. 37

3Fatimatuz Zahra, "Jejak Sejarah Pergeseran Identitas Agamis menjadi Pun-Kultur di Pati", AlA'Raf: Jurnal Pemikiran dan Filsafat, Vol. XV, No 1, 2018. hlm 80.

${ }^{4}$ Rahayu Permana, "Sejarah Masuknya Islam ke Indonesia", Artikel http://dinus.ac.id/repository/docs/ajar/3._SEJARAH-MASUKNYA-ISLAM-KE-INDONESIA_.pdf

${ }^{5}$ Ashadi Cahyadi, "Pembangunan dan Pemberdayaan Manusia Melalui Dana Desa: Pola dari Masa Lalu Hingga Sinergiritas yang Rancu", Jurnal Ilmiah Syiar, Vol. 19, No. 01, 2019. hlm. 49.
} 
disebut dengan hablum min Allahdan hablum min an-nas. Dimensi ini penting untuk diperhatikan oleh para aktifis dakwah agar bisa berjalan secara sinergis. ${ }^{6}$

Jika berhasil digali akar sejarahnya akan dijumpai unsur-unsur yang selama ini berhasil membawa Islam. Danandjaja menyebutkan peninggalan sebuah kebudayaan yang koletif tersebar dan diwariskan secara turun-temurun dengan berbagai macam bentuk dan versi baik tulisan, lisan, maupun yang lainnya. ${ }^{7}$ Di bumi Nusantara yang mayoritas penduduknya beragama Islam, hal yang menarik jika mengetahui sejarah awalnya agama Islam tersebut masuk ke Nusantara.

Menurut J. C Van Leur berdasarkan berbagai cerita perjalanan, dapat diperkirkan bahwa sejak $674 \mathrm{M}$ ada koloni-koloni Arab di Barat Laut Sumatera yaitu Barus. Melalui peninggalan sejarah di Kota Barus tentu tidak lepas dari kehidupan manusia sebagai objek dakwah, dan individual membutuhkan suatu kehidupan yang berpedoman pada Alquran dan Al-Hadits. Para syekh atau ulama yang ada di Barus meninggalkan corak yang sangat unik dan dapat dipahami. Mereka pernah membumikan ajaran aqidah dan berdakwah mengajak umat manusia yang belum beriman agar beriman kepada Allah SWT (memeluk agama Islam). ${ }^{8}$ Peneliti berpandangan bahwa perkembangan Islam melalui tulisan ini akan mengungkapkan jejak peninggalan Islam di Barus dan perkembang dakwahnya.

Menariknya, Joko Widodo meresmikan Kota Barus Kabupaten Tapanuli Tengah Provinsi Sumatera Utara sebagai Titik Nol Islam Nusantara di Indonesia. ${ }^{9}$ Literatur sejarah banyak menyebut bahwa Islam di Indonesia pertama kali hadir di Barus. Hal ini dibuktikan dengan keberadaan pemakaman Mahligai di Barus pada abad ke-7. Kota Barus yang banyak meningalkan corak sebuah identitas kultural bila berhasil diteliti jejak sejarahnya dapat dijadikan dasar bagi pengemban suatu wilayah atau negara. ${ }^{10}$

Keputusan penetapan Barus sebagai Titik Nol Islam Nusantra ternyata menimbulkan polemik dari sejarawan dan masyarakat tertentu. Selama ini yang masyarakat mengetahui

6Thoha Jahja Omar, “Ilmu Da'wah”, (Jakarta: Widjaya, 1971), hlm 4.

7James Danandjaja, "Faklor Indonesia: Ilmu Gosip Dongeng dan Lain-Lain”, (Jakarta: PT Temprint, 1991), hlm 2.

${ }^{8}$ Moch. Ali Aziz, "Diktat Mata Kuliah Dakwah", (Surabaya: Fakultas Dakwah IAIN Sunan Ampel, 1993), hlm. 3.

${ }^{9}$ Bagus Prihantoro Nugroho, "Menganal Barus sabagai Pusat peradaban Islam Tertua di Nusantara", diakses 26-10-2019, http://m.detik.com/news/berita/d-3456663/mengenal-barus-pusatperadaban-islam

${ }^{10}$ Bayu Dwi Nurwicaksono, "Falkor Lapindo sebagai Wawasan Geo-Culture dan Geo-mythologi Berbasis Kearifan Lokal dalam Pembelajaran Bahasa Indonesia Bagi Penutur Asing", Jurnal Pendidikan Bahasa dan Sastra, Vol. 13, No. 1, 2013. 
bahwa Aceh merupakan Islam pertama di Nusantara. Para akademisi juga meragukan penetapan Islam Nusantara di Kota Barus atau di Aceh. Sebab sejak lama, pembelajaran sejarah menempatkan Kerajaan Samudara Pasai di Aceh Darussalam sebagai pusat penyebaran pertama Islam. Perdebatan antara masuknya Islam ke nusantara ini menjadikan penulis untuk mengali sejarah Islam dan perkembangan dakwah di Kota Barus. Dalam tulisan ini peneliti akan menguraikan jejak peradaban Islam dan dinamika dawah yang ada di Kota Barus untuk mengetahui Islam pertama Nusantara.

\section{METODE}

Jenis penelitian ini adalah kualitatif (lapangan) dengan pendekatan sejarah, kritik, dan interpestasi. Skema yang peneliti bangun adalah, pertama Peneliti observasi atau terjun langsung ke destenasi historis Kota Barus di Tapanuli Tengah. Peneliti telah mewawancarai Dinas Pariwisata, masyarakat adat, dan tokoh agama yang ada di Kota Barus guna mencari data yang berkaitan dengan permasalahan. Sehingga metode purposive sampling digunakan. Kedua, sumber lain yang diperoleh berasal dari buku, artikel jurnal, berita terkait historis Barus. Ketiga, Peneliti sumber-sumber yang berkaitan dengan sejarah barus dipilah-pilah, dikritisi, dan diinterpretasi. Tahap ini akan dijelaskan jejak Islam dibarus dan dinamika perkembangnya. Jadi penelitian ini berusaha mengambarkan apa adanya atau memberikan gambaran yang lebih jelas tentang jejak Islam pertama dan dinamika perkembangannya di Barus, Kabupaten Tapanuli Tengah, Provinsi Sumatera Utara. Melalui serangkaian metode ilmiah ini, telah mampu mengungkapkan secara objektif apa yang terjadi di Barus.

\section{HASILDAN PEMBAHASAN}

\section{Jejak Dakwah Islam Nusantara di Barus}

Barus merupakan sebuah kecamatan yang berada di wilayah Kabupaten Tapanuli Tengah, Provinsi Sumatra Utara. Memiliki penduduk yang heterogen, mulai dari suku batak, minang, jawa, dan lainnya. Masyarakat membangun pekonomi melalui berbagai mata pencarian.Yakni sebagai petani, nelayan, wiraswasta,pegawai pemerintahan, dan lainnya. Agama mayoritas yang dianut oleh masyarakat Barus adalah Islam dan Kristen. Walaupun begitu masyarakatnya tetap saling bergantungan satu sama lain, saling memahami, saling menghargai dan terlihat harmonis.

Mengenai masuknya Islam ke Indonesia ada suatu kajian yakni seminar ilmiah yang diselenggarakan pada tahun 1963 di Kota Medan, yang menghasilkan hal-hal sebagai berikut :

a. Pertama kali Islam masuk ke Indonesia pada abad 1 H/ 7 M langsung dari Arab. 
b. Daerah pertama yang dimasuki Islam adalah Pesisir Sumatera Utara. Setelah itu masyarakat Islam membentuk kerajaan Islam Pertama yaitu Aceh.

c. Para dai pertama mayoritas adalah para pedagang. Pada saat itu disebarkan secara damai. $^{11}$

Berdasarkan pendapat tersebut peneliti mencari tahu sebab Kerajaan Silam berada di Aceh namun ajaran Islam itu sendiri belum ada kepastian di dalamnya. Pendapat lain masuk dan tersebarnya agama Islam didaerah Pesisir Sumatera Utara, sangat mungkin sudah didahului oleh singgahnya para pedagang muslim memasuki wilayah ini sejak abad ke-7 dan ke-8. Selanjutnya, daerah lain yang juga disinggahi oleh pedagang muslim adalah Perlak sebagaimna dicatat oleh Marcopolo seorang musafir dari Vanesia. ${ }^{12}$

Dalam berbagai sumber menyebutkan bahwa Islam sebelum didakwahkan ke Aceh mulamula datang menepak di Barus yang juga wilayah yang juga pernah menjadi kekuasaan Aceh. Hanya saja perlu dinyatakan bahwa Barus tidak pernah menjadi kerajaan Islam apalagi sebuah kekuatan politik Islam. Hanya ada dua kerajaan Islam pada awalnya, yakni Peureulak dan Pasai, selanjutnya Aceh Darussalam. Proses pencarian samudra untuk mewujudkan perintah seperti yang dimaksud Nabi SAW dalam mengembangkan dakwah menjadi tujuan utama dan mereka singgah di beberapa tempat. ${ }^{13}$ Informasi adanya kunjungan Barus secara langsung oleh pedagang Cina masa lampau dan India mencari dammar atau kapur barus yang paling tinggi mutunya. Sekitar abad 10 ada bukti menimbulkan kesan bahwa pedangang dari Timur Tangah mendatangi langsung Barus dan mencari dammar (kapur Barus) tersebut. ${ }^{14}$

Pertengahan abad ke-8 Masehi, Syarif Mekkah di zaman Khalifah Harun al-Rasyid bertitah dan menyiapkan kapal dari Jeddah yang dinakodahi oleh Syekh Ismail beserta Fakhri Muhammad (pernah menjabat sebagai Raja di Malbar) untuk menyiarakan Islam di Samudra. Kapal dimaksud mula-mula singgah di Fansuri Barus. Syekh Ismail dan rombongan turun kedaratan beberapa saat. Kemudian, menemukan beberapa orang untuk didakwahi disana serta meminta sekaligus mengajarkan meraka untuk membaca Alquran. Setelah dakwah selesai di wilayah Barus, Syekh Ismail meneruskan perjalanan mencari samudra, tetapi mereka singgah dahulu di Bandar Peureulak Aceh.

\footnotetext{
${ }^{11}$ Ahmad al-Usairy, "Sejarah Islam Sejak Zaman Nabi Adam Hingga Abad XX", (Jakarta: Akbar Media, 2003), hlm. 336.

${ }^{12 M i s r i s ~ A . ~ M u h s i n, ~ " K e s u l t a n a n ~ P e r u r e u l a k ~ d a n ~ D i s k u r s u s ~ T i t i k ~ N o l ~ P e r a d a b a n ~ I s l a m ~ N u s a n t a r a ", ~}$ Jurnal of Contomporary Islam and Muslim, Vol. 2, No. 2, 2018. hlm. 220.

${ }^{13}$ Ibid hlm 22

14Jane Drakard, "Sejarah Raja-Raja Barus Dua Naskah dari Barus", (Jakarta: Gramedia Pustaka Utama, 2003), hlm. 17.
} 


\section{Penetapan Barus sebagai Lokasi Penyebaran Islam Pertama di Indonesia}

Penetapan berangkat dari peresmian Presiden Republik Indonesia, Ir. Joko Widodo. Atas dasar kajian yang intensif dan permintaan masyarakat, Presiden menetapkan dan meresmikan Tugu Titik Nol Islam Nusantara. Menurut Hendri Susanto Tobing, Sekretaris Daerah Kabupaten Tapanuli Tengah, pemerintah daerah menyiapkan kehadiran Presiden Jokowi untuk meresmikan titik nol peradaban penyebaran agama (bukan hanya Islam) di seluruh Indonesia yang dimulai dari Barus.

Dijelaskan bahwa sejarah penyebaran agama-agama di Indonesia, terutama Islam, Nasrani, Hindu dan Budha dimulai dari Barus. Khusus untuk Muslim, sebagai buktinya adalah situs Mahligai dan Situs Papan Tinggi yang menyebarkan Islam kira-kira abad ke-5 masehi. Diikuti perkembangan selanjutnya yang masuk melalui Timur Tengah melalui Tapanuli Tengah ke seluruh Nusantara. Keterangan dan sekaligus argumentasi penetapan titik nol Islam di Barus.

Menurut satu keterangan, proses masuknya Islam ke Barus khususnya, Sumatera dan Nusantara pada umumnya terkait erat dan diawali dari perjalanan para pedagang Arab yang singgah di Barus. Peristiwa itu sudah dimulai sejak zaman Nabi Muahammad SAW, yaitu orang-pedagang Arab yang pergi berdagang ke CinaTiongkok dan mereka kebanyakan singgah di Bandar Barus terlebih dahulu. Misalnya kisah seorang pedagang Arab yang bernama Wahab bin Abu Kasbah dan rombongannya. Ingin berdagang ke Cina dan singgah di pulau Morsala, yang letaknya antara pantai Barus dan Sibolga.

Sumber ini juga menginformasikan bahwa misi dari pemerintah Madinah, dari Barus melanjutkan perjalanannya ke Tulang Bawang, Lampung, pusat pemerintahan Sriwijaya di Palembang, ke Brunei dan baru selanjutnya ke Kanton, Cina. Keterangan yang menyatakan orang Arab-Madinah menjadikan Barus tempat transit, jika dihubungkan dengan makammakam yang ada di situs Mahligai dan situs makam Papan Atas atau Tangga Seribu, membuktikan kebenarannya, karena yang dimakamkan di kedua situs makam tersebut umumnya dari Arab, seperti makam Syekh Mahmud yang berada di puncak bukit Tangga Seribu/Papan Atas dengan panjangnya mencapai delapan meter, pada nisannya menginformasikan bahwa almarhum berasal dari Tanah Arab.

Keterangan lain, yaitu dari Kitab Sejarah Melayu, yang menyebutkan bahwa Syekh Ismail yang berasal dari Mekah, khilafahnya di Madinah mau menuju Samudera Pasai, tetapi tidak tahu persis kawasan tujuannya. Ia memilih singgah lebih dahulu di Bandar Barus, dan memperkenalkan Islam kepada masyarakat setempat. Kemudian dari sana baru ia melanjutkan 
ke Pasai untuk menyebarkan Islam pula di sana. Dari ungkapan terakhir memberi sinyal bahwa Barus merupakan wilayah yang mula-mula menerima dan didatangi Islam. Kemudian baru ke wilayah lain, yaitu ke Peureulak dan Pasai. Hanya saja, walaupun Barus yang mula-mula menerima Islam, tetapi umat Islam di sana tidak menghasilkan atau tidak membentuk kekuasaan atau kerajaan Islam sebagai kekuatan politiknya, tetapi masyarakat Islam di Peureulak lah yang sukses mencapai kekuatan politik Islam pertama di Nusantara. ${ }^{15}$

Dengan demikian jelaslah bahwa memang ada kemungkinan pengislaman pertama berlangusung di Fansuri Barus dan wilayah ini pernah menjadi wilayah territorial kesultanan Aceh Darusslaam. Hal ini sangat beralasan seperti yang diungkapakan oleh T. Ibrahim Alfian karena secara geografis wilayahnya startegis yang terletak antara lauta Hindia dan Laut Cina selatan yang menghubungkan negeri-negeri sebalah timur seperti Cina dan Jepang dan dengan negeri-negeri sebelah Barat yaitu Anak Benua India, Persia, dan negara-negara Arab, Afrika serta dengan benua Eropa. Barus merupakan kawasan yang paling ujung Barat para pendatang-pendatang dari timur dan barat tentu menjadikan pelabuhan Barus sebagai tempat singgah dan perdagangan rempah-rempah termasuk kapur Barus yang demikian terkenal. Kawasan ini menjadi tempat bagi para pedagang menunggu giliran datang angin musim timur laut dan barat daya yang akan membawa mereka dan barang-barang dagangan ketempat tujuan masing-masing termasuk ke Peureulak.

\section{Jejak Peninggalan Peradaban Islam di Barus}

\section{a. Inskripsi Makam Mahligai}

Kompleks Makam Mahligai terletak di Desa Aek Dakka, sekitar 5 km dari Kecamatan Barus ke arah utara. Kompleks merupakan pemakaman terbesar bila dibandingkan dengan yang lainnya. Luasnya sekitar tiga hektar dan sekitarnya terdapat perkebunan karet. Komplek makam ini terletak di perbukitan. Nama makam Mahligai berasal dari kata "Mahligai" yang sama artinya dengan istana kecil pada zaman dahulu. Kemudian disebutlah kompleks ini sebagai "Makam Mahligai". ${ }^{16}$

Memiliki bentuk batu nisan di Makam Mahligai cukup beragam dan variatif, ini hampir sama dengan yang ditemukan pada makam-makam lain di wilayah Barus. Variasi bentuk batu nisan yang diamati dapat dikelompokkan menjadi beberapa tipe, yaitu:

\footnotetext{
15Ibid., hlm 223.

${ }^{16}$ Jahirudin Pasaribu, "Sejarah Ringkas Kota Barus Negeri Tua, Aej Dakka", Dokumen Tapanuli Tengah, tidak diterbitkan.
} 
1) Bentuk pilar/tiang bersisi delapan atau oktagonal dengan motif hias utama bunga teratai, motif bunga, dan kaligrafi Arab. Jenis batu semacam ini mempunyai mahkota yang bentuknya seperti bunga teratai.

2) Batu nisan tiang silinder di mana puncak atau mahkotanya berbentuk teratai. Jenisnya polos, tetapi sebagian di antaranya berhiaskan motif kerawangan bertema sulur-sulur yang dikombinasikan dengan motif geometri.

3) Bentuk nisan pipih bagian atas dipotong dengan lengkung-lengkung kecil, dengan kesan bergerigi.

4) Bentuk nisan berupa potongan papan batu yang pipih dengan bagian atasnya melengkung, seperti bentuk lunas kapal atau lengkung gaya Persia. Motif hiasnya bertema tumbuh-tumbuhan dan bungabungaan dipahat dengan rancangan tertentu.

Masyarakatsetempatmeyakinibahwamakamtersebutialah para pedagangarab yang menyebarkan islam ke Barus dan pernah menjalin perdagan antara pribumi hingga kebagian Samudrai Pasai. Makam sebagai historis bahwa Islam pernah ada di Kota Barus pada Abad 6 Masehi. Kalimat Iman dan syahadat merupakan inskripsi yang paling dominan yang ditemukan di Barus karena dimakam Mahligai terdapat kalimat syahadat di Makam Mahligai.

\section{b. Inskripsi Makam Tuan Makhdum}

Area pemakaman Tuan Makhdum berada di Desa Patupangan, Kecamatan Barus, di kaki perbukitan yang landai. Bentuk nisannya sama dengan batu nisan di Makam Mahligai. Dibandingkan dengan nisan-nisan Aceh, maka nisan termasuk dalam tipologi B2 atau tipe G menurut Othman. Pada tipe ini bentuk dasarnya adalah balok empat persegi, bahu cenderung datar atau sedikit ditinggikan, kepala berundak satu atau lebih, hiasan pada bagian kaki dan pinggang biasanya geometris dengan bebungaan di setiap sudutnya. Kaligrafi atau inskripsi dipenuhi pada sisi kanan-kiri-atas-bawah, dan tengah nisan. ${ }^{17}$

Adapun inskripsi yang terdapat pada masing-masing batu nisan adalah sebagai berikut: Pertama, pada nisan, yang baru bisa dibaca sementara yaitu kalimat la ilaha illallah, Muhammadurrasulullah (Tiada Tuhan selain Allah, Muhammad utusan Allah) di seluruh sisi. Kalimat yang sama juga terdapat pada nisan. Kedua, Pada nisan inskripsi bertuliskan (mālik almulki" žū al-jalāli wa alikrām; yang memiliki kekuasaan, memiliki kebesaran dan kemuliaan) sedang pada nisan lain, inskripsi bertuliskan (innā fataḥnă laka fatḥan mubinā; sungguh, Kami telah memberikan kepadamu kemenangan yang nyata).

${ }^{17}$ Ery Soedewo, dkk, Perekaman Peninggalan Sejarah Budaya Islam di Sumatera Utara, hlm 3-5. 
Ketiga ayat Alquran ini menunjukkan bagaimana kekuasaan Tuhan yang tiada bandingannya dengan manusia. Surah Ali-Imran ayat 26 dan surah Ar-Rahman ayat 27, jelas sekali bagaimana Allah menunjukkan sifat jalaliyahnya, yang bermakna banwa Tuhan sematamata yang mempunyai kekuasaan petala langit dan bumi. Dari ayat ini, secara sekilas tampak bertentangan dengan sifat-sifat jamaliyah (keindahan) Tuhan yang selalu menunjukkan kasih sayangnya kepada semua makhluknya. ${ }^{18}$

Dalam terminologi sosiologi agama, Tuhan seringkali berifat mendua yang disebut dengan misterium tremendum at fascinocum, yang pada satu sisi keras, galak, maha dahsyat, tapi di sisi lain ia maha penyayang, penyantun, dermawan dll. Namun, bila telaah lebih jauh ketika Tuhan menunjukkan jamaliyahnya, ini pertanda bahwa sebenarnya Allah sayang kepada makhluknya, di mana dengan menunjukkan sifat jalaliyah agar manusia menuju sifat jamaliyah-Nya.

\section{c. Inskripsi Makam Papan Tinggi}

Makam ini terletak di atas bukit dengan ketinggian kurang lebih $720 \mathrm{M}$ dia atas permukaan laut. Di atas perbukitan ini terdapat tanah yang datar sekitar $20 \times 15 \mathrm{M}$. Di lokasi tanah inilah terdapat delapan makam, dan hanya satu yang ada inskripsinya berbahasa Arab. Makam ini barangkali terpanjang yang ada di Barus, bahkan mungkin di Indonesia dengan diameter sekitar 8,15 M, dan tinggi nisannya $135 \mathrm{~cm}$. Diperkirakan tokoh yang dimakamkan ini adalah seorang sufi bernama Syekh Mahmud yang tertera dalam inskripsinya. ${ }^{19}$ Syekh Machmud yang lahir pada idup pada masa Umar Bin Khatab sebagai seorang khalifah. Beberapa orang yang berbeda juga penasaran untuk mengukur panjang ukuran makam.

Tidak semua makam diberi tanda batu nisan dan tidak berukirkan batu alam. Bentuk batu nisan menggunakan jenis batuan granit putih berbintik hitam yang menunjukkan batu nisan yang berasal dari Barus. Batu nisan penanda kepala makam berbentuk pipih dengan bagian kepala berupa lingkaran. Sementara batu nisan penanda kaki makam berbentuk pipih dan bagian kepala dipahat bergelombang. Tipologi nisan yang ada di makam ini adalah berbeda dengan nisan yang ada di Aceh. Batu nisan ini lebih bercorak kepada tipe surya majapahit yang ada di Jawa. Bila dilihat dari jenis kaligrafinya, maka inskripsi yang ada pada kompleks makam ini bercorak sulus. ${ }^{20}$

${ }^{18}$ Masmedia Pinem, “Inskripsi Islam pada Makam-Makam Kuno Barus”, Jurnal Lektur Keagamaan, Vol. 16, No. 1, 2018. hlm 109.

19Ibid,. hlm. 118.

${ }^{20}$ Pidia Amelia, "Pengelolahan Warisan Budaya Kawasan Barus", Tesis, Arkeologi Universitas Gadjah Mada,2017. hlm 6. 
Ada tiga inskripsi yang dapat dibaca dengan jelas yaitu, satu ayat Alquran dan dua hadis Nabi. Adapun inskripsi yang dikutip dari Alquran yaitu, (kullu sya'in hālikun illa wajhahu, segala sesuatu pasti binasa, kecuali Allah) yang artinya segala sesuatu akan binasa kecuali wajah-Nya. Sementara kutipan hadis pada nisan ini berbunyi: qala al-nabi sallallahu 'alaihi wasallama almu'minu hayyun fi al-darain, yang artinya Nabi Muhammad bersabda: orang mukmin itu hidup di dunia zaman. Sedangkan inskripsi ketiga yaitu hadis Nabi yang terdapat di bagian kepala yang berbunyi: la ilaha illallah, Muhammadurrasulullah, qala al-nabi 'alaihi wasallama: al-mu'minūna la yamütūna bal yungalūna min dārin ilā dārin, artinya, tiada Tuhan selain Allah, Muhammad utusan Allah, bersabda Nabi 'alaihi al-salām (semoga keselamatan baginya): orang-orang beriman itu tidaklah meninggal dunia, akan tetapi mereka berpindah dari satu tempat ke tempat yang lain ${ }^{21}$.

Pada hakikatnya Kawasan Barus adalah ruang tempat warisan budaya berada yang tidak hanya terfokus pada hasil budaya bendawi (benda, bangunan, struktur dan situs) tetapi berkaitan dengan konteks lingkungan alami atau bentukan masyarakat pendukungnya pada masa lalu. Berdasarkan pemaparan tersebut dapat diartikan bahwa setiap tinggalan arkeologi tidak dapat dipisahkan dengan konteks lanskapnya, terutama untuk kepentingan pelestarian warisan budaya. Dan jejak islam di Barus baru terdapat Makam Syekh Mahmud dan ajaran yang telah disebarnya serta ada banyak makam para penyebar islam yang lebih lama daripada kerajaan Samudra Pasai. Untuk itu ajaran islam pertama di Nusantara ialah di Barus sedangkan puncak kejayaan ialah Aceh.

\section{Perkembangan Dakwah di Barus}

Dakwah mengajak manusia dengan cara bijaksana kepada jalan yang benar sesuai dengan perintah Tuhan, untuk keselamatan dan kebahagiaan mereka di dunia dan akhirat. ${ }^{22}$ Digunakan Alquran agar umat Islam mencontohi Nabi Muhammad SAWdalam kehidupan mereka.23Prinsip dakwah yakni keharusan mengajak kepada jalan Allah SWT,meskipun dakwah telah memilih konotasi sebagai pemahaman, gerakan dan pengorganisasian dalam menyampaikan pesan-pesan Islam dalam prakteknya takssemudah yang dipikirkan. Oleh karena itu perlu penegasan lebih lanjut mengenai pertimbanganpertimbangan psikologis maupun sosiologis da'i dan mad'u.

\footnotetext{
${ }^{21}$ Masmedia Pinem, Inskripsi Islam pada Makam-Makam Kuno Barus, hlm. 122.

22Wahidin Saputra, "Pengantar Ilmu Dakwah", (Jakarta: Rajawali Pers, 2012), hlm. 1.

${ }^{23}$ Kamarul Azmi Jasmi, "Qudwah Hasanah", (Fakulti Tamadun Islam: Universiti Teknologi Malaysia, 2016), hlm. 133.
} 
Secara psikis, nurani tindakan berdakwah merupakan panggilan bagi setiap orang yang beriman dan berilmu (da'i) sesuai kecakapannya masing-masing. Sementara bagi mad'u harus mengikuti seruan-seruan tersebut. Hal ini mesti tertanam dalam batin orang beriman. Kekukatan dan keyakinan akan dakwah islam sebagai imlementasi iman dak aktivitasi saleh akan teraktialisasi melalui aktivitas-aktivitas kesehariannya.24Islam memiliki kenegaraan yang menjujung tinggi nilai-nilai kesejahteraan bagi semua warga negara tanpa diskiriminasi. Secara umum konsep Islam dilandaskan pada etika dan moralisatas. ${ }^{25}$

Peran dakwah kontemporer sangat membertimbangan suatu kewajiban kebijakan Islam di waktu Barus berkomunikasi melalui laut dan kapal-kapal berlabuh untuk mengangkut hasilhasil dari seluruh daerah Barus. ${ }^{26}$ Peninggalan Kota Barus sedikit jumlahnya, karena kota nya sekarang mempunyai sejarah yang masih baru, dan kebanyakan bahan-bahan bangunannya terbuat dari kayu. Pada hakikatnya Kawasan Barus adalah ruang tempat warisan budaya berada yang tidak hanya terfokus pada hasil budaya bendawi (benda, bangunan, struktur dan situs) tetapi berkaitan dengan konteks lingkungan alami atau bentukan masyarakat pendukungnya pada masa lalu.

Dakwah itu dibagi dua yaitu tujuan jangka pendek dan tujuan jangka panjang. Tujuan jangka pendek yang dimaksud adalah agar manusia mematuhi ajaran Allah SWT dan RasulNya dalam kehidupan keseharian. Sehingga tercipta manusia yang berakhlak mulia, dan tercapainya individu yang baik (khoiru al-fardiyah),keluarga yang sakinah/harmonis (khoiru alusrah), komunitas yang tangguh (khoirul al-jama'ah), masyarakat madani (khoiru al-ummah). Pada akhirnya akan membentuk bangsa yang sejahtera dan maju (khoiru albaldah) atau dalam istilah yang disebut dalam Alquran yaitu: Baldatun thoyyibatun wa robbun ghofur. Ini lah yang membuat pada masa lalu Syekh Mahmud mengajarkan agama Islam ke Kota Barus memalui perdagangan dan menyebarkan islam ke Barus dan mengajarkan alquran pada masyarakat setempat.

Peneliti mengamati Barus mulai tergerus dari gelora kota yang bernuansa Islami. Ini dapat dibuktikan dengan banyaknya gereja. Menurut Rizki, tokoh masyarakat di Barus,disebabkan pada masa lalu penjajah masuk ke Barus dan pribumi terdesak keAceh dan mereka membuat kerajaan disana.27Semakin lama masyarakat yang tinggal di Barus tidak lagi beragama Islam karenapengunjung yang silih berganti dari pelabuhan maka agama masyarakat

${ }^{24}$ Acep Aripudin, “Dakwah Antar Budaya”, (Bandung: PT Remaja Rosdakarya, 2012), hlm. 45.

${ }^{25}$ Ihsan Rahmat dan Netta Agusti, "Manajemen Sumber Daya Manusia Islam: Sejarah, Nilai, dan Benturan, Jurnal Ilmiah Syi'ar, Vol. 18, No. 1, 2018. hlm. 23.

26Ibid., hlm 31

27Wawancara pada 29 Juni 2019. 
tidak lagi Islam. Namun sejarah Islam masih dikenang disana, pemerintah KabupatenTapanuli Tengah berupaya mempromosikan Kota Barus sebagai kota relegius.

Da'I merupakan subyek dakwah yang dipilih langsung oleh Allah juga subyek (perintah berdakwah) itu ditunjukkan kepada seluruh umat beriman. Untuk itu, dapat ditegaskan bahwa subyek dakwah adalah mencakup setiap muslim dari seluruh lapisan masyarakat tanpa kecuali, laki-laki perempuan dengan tingkat kemampuan masing masing kapan dan dimanapun mereka berada. dipahami bahwa subyek dakwah adalah setiap muslim perempuan dan laki-laki baligh dan berakal 'tanpa syarat' ulama atau cendikiawan muslim. Karena kewajiban berdakwah seperti telah dijelaskan dalam hukum dakwah, sudah merupakan beban atau tuntunan atau setiap muslim seluruhnya.Namun, perlu disadari bahwa inti dari pelaksana dakwah (subyek) adalah bagaimana upaya da'i bagaimana masyrakat mengerjakan amal yang baik dan meninggalkan yang buruk. ${ }^{28}$

Namun, dai di Kota Barus sangatlah kurang hal ini sesesuai yang dikatakan Rizki seorang ustadz bahwa kurangnya pendakwah membuat kejayaan Islam di Kota Barus mengalami kemunduran, pengajian juga jarang dilakukan dan pergaulan remaja juga campur baur. Para masyarakat Barus perlu perubahan secara agama Islam agar perkembangan dakwah tetap ada. Pentingnya dakwah islamiyyah agar masyarakat dapat menerima dakwah dengan lapang dada, tulus dan ikhlas maka penyampaian dakwah harus melihat situasi dan kondisi masyarakat.

\section{KESIMPULAN}

Berdasarkan Paparan tersebut dikembangkan dalam penelitian selanjutnya mengenai dakwah Islam dibarus yang sering disebut sebagai pintu masuknya Islam pertama di Indonesia. Barus merupakan wilayah yang mula-mula menerima dan didatangi Islam. Kemudian baru ke wilayah lain, yaitu ke Peureulak dan Pasai. Hanya saja, walaupun Barus yang mula-mula menerima Islam, tetapi umat Islam di sana tidak menghasilkan atau tidak membentuk kekuasaan atau kerajaan Islam sebagai kekuatan politiknya, tetapi masyarakat Islam di Peureulak lah yang sukses mencapai kekuatan politik Islam pertama di Nusantara. Pembuktia bahwa pemakaman dan ajarana Islam oleh Syekh Mahmud di terapkan pertama di Barus namun kejayaan Islam di buktikan oleh kerajaan Samudra Pasai. Kota Barus mengalami kemunduran, pengajian juga jarang dilakukan dan pergaulan remaja juga juga campur baur. Para masyarakat Barus perlu perubahan secara agama Islam agar perkembangan dakwah tetap ada. Pentingnya dakwah islamiyyah agar masyarakat dapat menerima dakwah dengan lapang

28Salamadanis, “Dakwah dalam Perspektif Al-Qur'an", (Jakarta: The Minangkabau,2002), hlm. 59. 
dada, tulus dan ikhlas maka penyampaian dakwah harus melihat situasi dan kondisi masyarakat.

\section{DAFTAR RUJUKAN}

Al-Usairy, Ahmad. "Sejarah Islam Sejak Zaman Nabi Adam Hingga Abad XX", Jakarta: Akbar Media, 2003.

Aripudin, Acep. "Dakwah Antar Budaya”, Bandung: PT Remaja Rosdakarya, 2012.

Amelia, Pidia. "Pengelolahan Warisan Budaya Kawasan Barus", Tesis, Arkeologi Universitas Gadjah Mada, 2017.

A Muhsin, Misris. "Kesultanan Perureulak dan Diskursus Titik Nol Peradaban Islam Nusantara", Jurnal Of Contomporary Islam and Muslim. Vol. 2 No. 2, 2018.

Aziz, Moh. Ali.“Ilmu Dakwah”, Jakarta: Kencana, 2004.

."Diktat Mata Kuliah Dakwah", Surabaya: Fakultas Dakwah IAIN Sunan Ampel, 1993.

Azmi Jasmi, Kamarul. "Qudwah Hasanah", Fakulti Tamadun Islam: Universiti Teknologi Malaysia, 2016.

Danandjaja, James. "Faklor Indonesia: Ilmu Gosip Dongeng dan Lain-Lain”, Jakarta: PT Temprint 1991.

Drakard, Jane . "SejarahRaja-Raja Barus Dua Naskah dari Barus", Jakarta: Gramedia Pustaka Utama, 2003.

Dwi Nurwicaksono, Bayu.“Falkor Lapindo sebagai Wawasan Geo-Culture dan Geo-mythologi Berbasis Kearifan Lokal dalam Pembelajaran Bahasa Indonesia Bagi Penutur Asing", Jurnal Pendidikan Bahasa dan Sastra, Vol. 13, No. 1, 2013.

Ery Soedewo dk, Jahirudin. "Perekaman Peninggalan Sejarah Budaya Islam di Sumatera Utara”. Jahja Omar, Thoha. "Ilmu Da'wah", Jakarta: Widjaya, 1971.

Pasaribu, Jahirudin, Sejarah Ringkas Kota Barus Negeri Tua, Aej Dakka, Tapanuli Tengah

Permana, Rahayu. Sejarah Masuknya Islam ke Indonesia, Artikel http://dinus.ac.id/repository/docs/ajar/3._SEJARAH-MASUKNYA-ISLAM-KEINDONESIA_.pdf

Pinem, Masmedia. "Inskripsi Islam Pada Makam-Makam Kuno Barus", Jurnal Lektur Keagamaan, Vol. 16, No. 1, 2018.

Poesponegoro, Djoened.,dan Nugroho Notosusanto, Mawati (ed), "Sejarah Nasional Indonesia II", Jakarta : Balai Pustaka, 1984.

Rahmat, Ihsan., dan Netta Agusti, "Manajemen Sumber Daya Manusia Islam: Sejarah, Nilai, dan Benturan, Jurnal Ilmiah Syi'ar, Vol. 18, No. 1, 2018.

Salamadanis, "Dakwah dalam Prefektif Al-Qur'an", Jakarta : The Minangkabau, 2002.

Saputra, Wahid."Pengantar Ilmu Dakwah”, Jakarta: Rajawali Pers, 2012. 
JURNAL ILMIAH SYIAR

Jurusan Dakwah, FUAD, IAIN Bengkulu

https://ejournal.iainbengkulu.ac.id/index.php/syiar

Vol. 19, No. 02, Desember 2019; hlm. 168-181

Zahra, Fatimatuz "Jejak Sejarah Pergeseran Identitas Agamis menjadi Pun-Kultur di Pati", AlA'Raf: Jurnal Pemikiran dan Filsafat, Vol. XV, No 1, 2018. 